\title{
A Case Series of Patients with Pancreatic Cancer and Cholangiocarcinoma Treated with nab-Paclitaxel at a Single Institution
}

\author{
Michael P. Kolinsky, Michael B. Saywer, Jennifer L. Spratlin \\ Department of Medical Oncology, Cross Cancer Institute, Edmonton, Canada \\ Email: Michael.sawyer@alberthealthservices.ca
}

Received 18 April 2014; revised 10 May 2014; accepted 18 May 2014

Copyright (C) 2014 by authors and Scientific Research Publishing Inc.

This work is licensed under the Creative Commons Attribution International License (CC BY). http://creativecommons.org/licenses/by/4.0/

(c) (7) Open Access

\begin{abstract}
Background: Locally advanced or metastatic pancreatic cancer patients have a poor prognosis with median survival less than 12 months. Nanoparticle albumin bound (nab)-paclitaxel is a novel agent that has demonstrated antitumor effects in cancers that overexpress the albumin binding protein SPARC (secreted protein acidic and rich in cysteine), which includes pancreatic cancer. A recent phase III trial comparing nab-paclitaxel and gemcitabine to gemcitabine alone demonstrated a survival advantage in patients with previously untreated metastatic pancreatic cancer. Here we present our local experience with this drug in patients with gastrointestinal malignancies. Methods: Patients treated with $n a b$-paclitaxel for gastrointestinal malignancies at the Cross Cancer Institute in Edmonton, Alberta, Canada were identified and these patient's medical records were interrogated for data. Results: Three patients with pancreatic cancer and two with cholangiocarcinoma have been treated with nab-paclitaxel at the Cross Cancer Institute. Three patients achieved stable disease, while one had a partial response, and one had progressive disease after the first assessment. Median time to progression was 3.7 months. Median overall survival (OS) was 32.5 months. Median OS from initiation of nab-paclitaxel was 7.2 months. Patients tolerated treatment with $n a b$-paclitaxel well with only one patient requiring treatment modification due to neutropenia. Conclusion: The experience at this single center supports published evidence that nabpaclitaxel is a safe and effective therapy in pancreatic cancer, but also suggests that it may have activity in cholangiocarcinoma, which to our knowledge is the first published evidence of this in humans.
\end{abstract}

\section{Keywords}

nab-Paclitaxel, Pancreatic Cancer, Cholangiocarcinoma, Case Series 


\section{Introduction}

Pancreatic cancer is the fourth leading cause of cancer deaths in Canada, responsible for an estimated 4300 deaths in 2013 nationally, 380 of which will occur in Alberta [1]. Most patients have locally advanced or metastatic disease at presentation [2]. These patients have a uniformly poor prognosis with a median overall survival (OS) less than 12 months despite multi-drug chemotherapy regimens [3]. Even amongst resectable patients, prognosis is poor with 5-year OS rates of approximately $20 \%$ [4].

Systemic therapy options are limited for metastatic pancreatic cancer patients. The current standard of care for patients with good performance status and no significant hepatic dysfunction is FOLFIRINOX (5-flurouracil (5FU), leucovorin, irinotecan, and oxaliplatin) [3]. However, this regimen is associated with substantial toxicity and many patients are not eligible to receive this intensive treatment. For patients unfit for FOLFIRINOX, gemcitabine has been the first line option of choice [4] [5]. After progression on gemcitabine, oxaliplatin and 5FU, (OFF regimen) has demonstrated an OS advantage compared to 5FU alone [6].

Nanoparticle albumin bound (nab)-paclitaxel is a novel agent that has demonstrated antitumor effects in cancers that overexpress the albumin binding protein SPARC (secreted protein acidic and rich in cysteine), which includes pancreatic cancer, as well as breast cancer and melanoma [7]. SPARC is an extracellular matrix (ECM) glycoprotein that interacts with other components of the ECM and growth factors to regulate ECM production, cell adhesion, and the cytoskeletal architecture of certain cell types [8] [9]. When overexpressed, SPARC has been associated with invasion, metastatic dissemination, and a poor prognosis in a variety of malignancies [8] [9]. SPARC overexpression has been shown to lead to accumulation of albumin-bound drugs within tumors. Animal studies have shown that nab-paclitaxel has higher intratumoral levels and greater anti-tumor activity than conventional paclitaxel [10] [11]. Furthermore, unlike conventional paclitaxel, nab-paclitaxel is watersoluble and does not require Cremophor ${ }^{\circledR}$ EL in its formulation, and therefore avoids side effects that are associated with this agent, which includes severe anaphylactoid hypersensitivity reactions, neutropenia, and peripheral neuropathy [11]-[13].

The phase I/II trial of first line nab-paclitaxel with gemcitabine in metastatic pancreatic cancer patients showed a median OS of 12.2 months in those patients who received the maximum tolerable dose [7]. Patients that expressed high SPARC levels had a significantly longer OS than those with low SPARC levels. Treatment was generally well tolerated with the most common grade 3 toxicity being neutropenia. An accompanying preclinical study using patient derived tumor xenografts in mice treated with either gemcitabine, nab-paclitaxel, or the combination found that tumor regression occurred at rates of 24\%, 36\%, and 55\% respectively. Furthermore, animals treated with both drugs had significantly higher intratumoral gemcitabine concentrations compared to those animals receiving gemcitabine alone, suggesting a synergistic effect of co-administration. This appears to be due to nab-paclitaxel reducing cytidine deaminase levels, which is the main enzyme involved in metabolizing gemcitabine [14].

These encouraging results led to a phase III trial comparing the combination of nab-paclitaxel and gemcitabine to gemcitabine alone in previously untreated metastatic pancreatic cancer patients. Results of this study were recently published and demonstrated a significantly better overall progression free survival (PFS, 5.5 vs. 3.7 months) and OS (8.5 vs. 6.7 months) [15]. As nab-paclitaxel represents an emerging and exciting new treatment option for metastatic pancreatic cancer patients, we wish to report our local experience with this drug in patients with gastrointestinal malignancies. A total of five patients have been treated with this drug at the Cross Cancer Institute: 3 with pancreatic cancer and 2 with cholangiocarcinoma. While nab-paclitaxel has not been studied in patients with cholangiocarcinoma, this cancer shares the same embryologic origin as pancreatic cancer and may have similar biology. Furthermore, a multicentre phase II trial is planned to investigate the combination of gemcitabine and nab-paclitaxel in biliary malignancies. We intend to present a case series with descriptive outcomes and toxicities, as well as compare our outcomes to historically expected outcomes in patients with these malignancies.

\section{Methods}

This study was reviewed and approved by the local Research Ethics Board at our institution. Patients were included in this study if they had been treated with nab-paclitaxel for advanced gastrointestinal malignancies at the Cross Cancer Institute in Edmonton, Alberta, Canada. Advanced disease was defined as either metastatic or locally advanced, unresectable disease. These patients were identified by their treating physicians, and their medical records, both electronic and paper were used to extract data. 
Response was defined according to RECIST criteria (version 1.1) [16]. OS was defined as the time from diagnosis of advanced disease to either time of death or time of last follow. Time to progression (TTP) was defined as time from initiation of nab-paclitaxel to time of disease progression. Median values for both OS and TTP were calculated and stratified based on primary disease site. Toxicity assessment was based on the treating physician's description, as no formal symptom assessments were carried out, as these patients were not being treated on clinical trial.

\section{Results}

\subsection{Baseline Characteristics}

A total of five patients were treated with nab-paclitaxel for gastrointestinal malignancies from July 26, 2011 to May 31, 2013 (Table 1). Three patients had pancreatic adenocarcinoma, while two had cholangiocarcinoma. All patients had metastatic disease at the time of initiation of nab-paclitaxel. All patients had at least one line of therapy prior to $n a b$-paclitaxel treatment, with one patient having 4 lines of treatment prior.

\subsection{Treatment}

All patients were treated with weekly nab-paclitaxel for the first 3 weeks of a 4-week cycle, with the exception of one patient (patient \#3). This patient was neutropenic following the first treatment of nab-paclitaxel, and therefore had day 8 omitted from the first and all subsequent cycles. Three patients were treated with $100 \mathrm{mg} / \mathrm{m}^{2}$, and two with $125 \mathrm{mg} / \mathrm{m}^{2}$. All patients were treated with nab-paclitaxel monotherapy, with the exception of patient \#3, who received nab-paclitaxel alone for 4 cycles, and upon progression was treated with nab-paclitaxel and gemcitabine in combination for a further 4 cycles until progression (Table 2).

\subsection{Response}

Three patients achieved stable disease, while one had a partial response, and one had progressive disease after

\begin{tabular}{|c|c|c|c|c|c|c|}
\hline Patient & Gender & $\begin{array}{l}\text { Age at start of } \\
\text { nab-paclitaxel }\end{array}$ & Histology & $\begin{array}{l}\text { Sites of } \\
\text { metastatic } \\
\text { disease }\end{array}$ & Prior therapies & $\begin{array}{l}\text { Best response to } \\
\text { prior therapy }\end{array}$ \\
\hline 1 & Male & 72 & $\begin{array}{l}\text { Pancreatic } \\
\text { adenocarcinoma }\end{array}$ & Bone, lung & Gemcitabine & Stable \\
\hline 2 & Female & 51 & $\begin{array}{c}\text { Pancreatic } \\
\text { adenocarcinoma }\end{array}$ & Liver, lung & $\begin{array}{l}\text { 5FU (adjuvant); gemcitabine and } \\
\text { tremelimumab*; OFF }\end{array}$ & Stable \\
\hline 3 & Male & 59 & $\begin{array}{c}\text { Pancreatic } \\
\text { adenocarcinoma }\end{array}$ & Lung & Gemcitabine and tremelimumab*; OFF & Stable \\
\hline 4 & Male & 74 & Cholangiocarcinoma & Bone, lung & Cisplatin and gemcitabine & Progression \\
\hline 5 & Female & 67 & Cholangiocarcinoma & $\begin{array}{l}\text { Liver, } \\
\text { lymph nodes }\end{array}$ & $\begin{array}{l}\text { Paclitaxel, carboplatin, and etoposide; } \\
\text { gemcitabine and 5FU; afatinib and pemetrexed*; } \\
\text { regorafenib drug interaction study }\end{array}$ & Partial response \\
\hline
\end{tabular}

*Treated on clinical trial.

Table 2. Treatment and response.

\begin{tabular}{|c|c|c|c|c|c|c|c|}
\hline Patient & $\begin{array}{l}\text { Treatment } \\
\text { scedule }\end{array}$ & $\begin{array}{l}\text { \# of cycles of } \\
\text { nab-paclitaxel }\end{array}$ & Response & TTP (mos) & $\begin{array}{c}\text { Survival from } \\
\text { nab-paclitaxel start } \\
\text { (mos) }\end{array}$ & OS (mos) & Further therapies \\
\hline 1 & $\begin{array}{l}100 \mathrm{mg} / \mathrm{m}^{2} \\
\text { weekly } 3 / 4\end{array}$ & 7 & Progression ${ }^{*}$ & 1.5 & 7.2 & 20.5 & None \\
\hline 2 & $\begin{array}{l}125 \mathrm{mg} / \mathrm{m}^{2} \\
\text { weekly } 3 / 4\end{array}$ & 9 & $\begin{array}{l}\text { Partial } \\
\text { response }\end{array}$ & 8.8 & 20.7 & 32.5 & $\begin{array}{l}\text { MEK + BRAF inhibitor } \\
\text { combination }^{\dagger} \text {, irinotecan }\end{array}$ \\
\hline 3 & $125 \mathrm{mg} / \mathrm{m}^{2} \mathrm{q} 2$ & $\begin{array}{l}4 \text { alone, then } 4 \\
\text { with gemcitabine }\end{array}$ & Stable & 3.7 & 9.8 & 35.9 & None \\
\hline 4 & $\begin{array}{l}100 \mathrm{mg} / \mathrm{m}^{2} \\
\text { weekly } 3 / 4\end{array}$ & 4 & Stable & 2.8 & 3.3 & 11.7 & None \\
\hline 5 & $\begin{array}{l}100 \mathrm{mg} / \mathrm{m}^{2} \\
\text { weekly 3/4 }\end{array}$ & 7 & Stable & 3.8 & 6.6 & 41.4 & None \\
\hline
\end{tabular}

${ }^{*}$ Treated beyond radiologic progression for clinical benefit. ${ }^{\dagger}$ Treated on clinical trial. 
the first assessment. TTP varied between 1.5 and 8.8 months, with a median of 3.7 months. OS varied from 11.7 to 41.4 months, with a median OS of 32.5 months. Median OS from initiation of nab-paclitaxel was 7.2 months, with a range of 3.3 - 20.7 months (Table 2).

\subsection{Toxicity}

Patients tolerated nab-paclitaxel treatment well with only one patient requiring treatment modification. This patient experienced neutropenia following the first nab-paclitaxel treatment, and therefore had the day 8 treatment omitted from this and all subsequent cycles. One patient developed painful neuropathy in his fingers following the second treatment cycle.

\section{Discussion}

Pancreatic cancer is a leading cause of cancer deaths with few effective therapies and a uniformly poor prognosis for the majority of patients who present with locally advanced or metastatic disease [1]-[4]. Pancreatic cancer has been found to overexpress SPARC, an ECM glycoprotein that is associated with more aggressive cancers and a poor prognosis [8] [9]. SPARC overexpression has been demonstrated to facilitate accumulation of albumin-bound drugs in cancer cells, including nab-paclitaxel. When compared to conventional Cremophor ${ }^{\circledR}$ EL based paclitaxel, treatment with nab-paclitaxel has been found to increase intratumoral paclitaxel concentrations and response rates in preclinical studies [10] [11]. Furthermore, nab-paclitaxel given in combination with gemcitabine, higher intratumoral gemcitabine concentrations were found when compared to patients receiving gemcitabine alone, implying a synergistic effect [7] [14].

nab-Paclitaxel represents a new therapy for metastatic pancreatic cancer patients, with phase III data showing an OS improvement of approximately 2 months when added to gemcitabine in the first line setting, compared to gemcitabine alone [15]. While there are no trial data to show efficacy in cholangiocarcinoma, there is reason to suspect that this treatment may show a similar benefit, due to a common embryologic origin.

In this case series, we report our experience of treating five patients with nab-paclitaxel with either pancreatic cancer or cholangiocarcinoma at a single academic oncology center. In this cohort of patients, nab-paclitaxel appeared to be a safe and effective therapy, with all but one patient achieving at least stable disease. The median time to progression was found to be 3.7 months with one patient achieving a remarkable 8.8 months of disease control (Table 2). Survival in this cohort is also remarkable for the fact that all but one patient survived significantly longer than the expected median OS for their respective diseases. For patients with metastatic pancreatic cancer, both gemcitabine monotherapy and FOLFIRINOX are acceptable first line options depending on patient performance status and hepatic function, with a median OS of 6.8 and 11.1 months respectively [3] [4]. Three pancreatic cancer patients in our cohort had an OS of 20.5, 32.5, and 35.9 months (Figure 1). The two cholan-

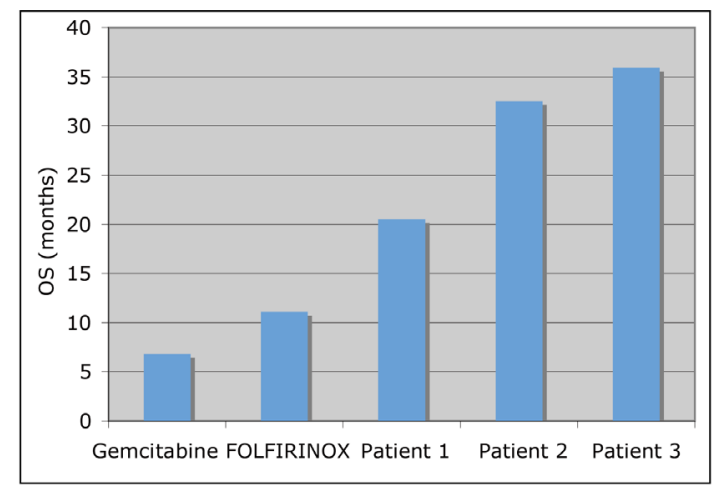

Figure 1. A comparison of expected median OS of patients with metastatic pancreatic cancer receiving first line chemotherapy compared to the OS of the reported patients with pancreatic cancer receiving nab-paclitaxel: the expected median OS for patients with metastatic pancreatic cancer receiving first line gemcitabine and FOLFIRINOX are 6.8 and 11.1 months respectively. Observed OS for the three reported patients treated with nab-paclitaxel for metastatic pancreatic cancer were 20.5, 32.5, and 35.9 months. 


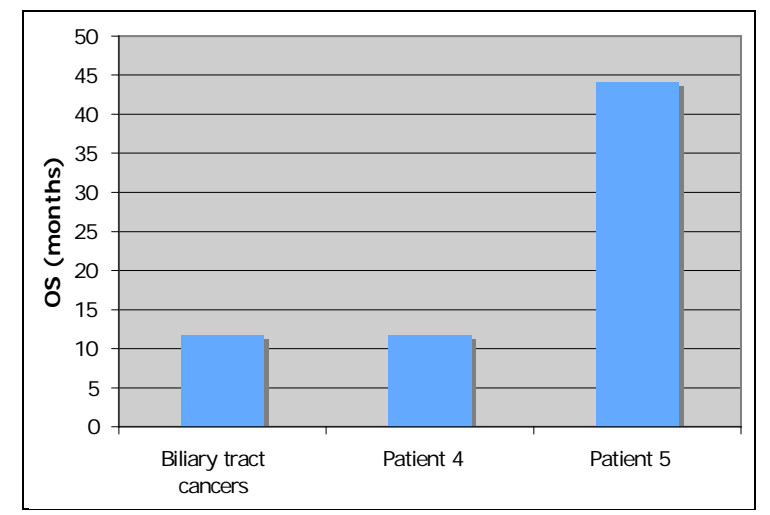

Figure 2. A comparison of expected median OS of patients with locally advanced or metastatic biliary tract cancers receiving first line chemotherapy compared to the OS of the reported patients with metastatic cholangiocarcinoma treated with nab-paclitaxel: The expected median OS of advanced biliary tract cancers patients, including cholangiocarinoma is 11.7 months. The observed OS for the two reported metastatic cholangiocarinoma patients treated with nab-paclitaxel was 11.7 and 41.4 months.

giocarcinoma patients had an OS of 11.7 and 41.4 months, compared to an expected median OS of 11.7 months for locally advanced or metastatic biliary tract cancers patients receiving first line chemotherapy (Figure 2) [17]. The median OS for our cohort of patients was 32.5 months.

Certainly little insight is to be had from the survival data of this cohort, given its small size, and likely selection bias of patients who were fit enough to receive ongoing chemotherapy after standard treatment and available clinical trials had been exhausted. Nonetheless, experience at this single center supports published evidence that nab-paclitaxel is a safe and effective therapy in pancreatic cancer, but also suggests that this drug may have activity in cholangiocarcinoma, which to our knowledge is the first published evidence of this in humans.

\section{References}

[1] Canadian Cancer Society’s Advisory Committee on Cancer Statistics (2013) Canadian Cancer Statistics. Canadian Cancer Society, Toronto. http://www.cancer.ca/ /media/cancer.ca/CW/cancer\%20information/cancer\%20101/Canadian\%20cancer\%20statistics/ canadian-cancer-statistics-2013-EN.pdf

[2] Neoptolemos, J., Stocken, D., Friess, H., Bassi, C., Dunn, J.A., Hickey, H., et al. for the European Study Group for Pancreatic Cancer (2004) A Randomized Trial of Chemoradiotherapy and Chemotherapy After Resection of Pancreatic Cancer. The New England Journal of Medicine, 350, 1200-1210. http://dx.doi.org/10.1056/NEJMoa032295

[3] Conroy, T., Desseigne, F., Ychou, M., Bouché, O., Guimbaud, R., Bécouarn, Y., et al. for the Groupe Tumeurs Digestives of Unicancer and the PRODIGE Intergroup (2011) FOLFIRINOX versus Gemcitabine for Metastatic Pancreatic Cancer. The New England Journal of Medicine, 364, 1817-1825. http://dx.doi.org/10.1056/NEJMoa1011923

[4] Alberta Health Services Pancreatic Cancer Clinical Practice Guideline. http://www.albertahealthservices.ca/hp/if-hp-cancer-guide-gi006-pancreas.pdf

[5] Burris, H., Moore, M., Andersen, G., Green, M.R., Rothenberg, M.L., Modiano, M.R., et al. (1997) Improvements in Survival and Clinical Benefit with Gemcitabine as First-Line Therapy for Patients with Advanced Pancreas Cancer: A randomized trial. Journal of Clinical Oncology, 15, 2403-2413.

[6] Tempero, M.A., Berlin, J., Ducreux, M., Haller, D., Harper, P., Khayat, D., et al. (2011) Pancreatic Cancer Treatment and Research: An International Expert Panel Discussion. Annals of Oncology, 22, 1500-1506. http://dx.doi.org/10.1093/annonc/mdq545

[7] Von Hoff, D.D., Ramanathan, R., Borad, M., Laheru, D.A., Smith, L.S., Wood, T.E., et al. (2011) Gemcitabine plus nab-Paclitaxel is an Active Regimen in Patients with Advanced Pancreatic Cancer: A Phase I/II Trial. Journal of Clinical Oncology, 29, 4548-4554. http://dx.doi.org/10.1200/JCO.2011.36.5742

[8] Podhajcer, O., Benedetti, L., Girotti, M., Prada, F., Salvatierra, E. and Llera, A. (2008) The Role of the Matricellular Protein SPARC in the Dynamic Interaction Between the Tumor and the Host. Cancer and Metastasis Reviews, 27, 691-705. http://dx.doi.org/10.1007/s10555-008-9146-7 
[9] Framson, P. and Sage E. (2004) SPARC and Tumor Growth: Where the Seed Meets the Soil? Journal of Cellular Biochemistry, 92, 679-690. http://dx.doi.org/10.1002/jcb.20091

[10] Desai, N., Trieu, V., Damascelli, B. and Soon-Shiong, P. (2009) SPARC Expression Correlates with Tumor Response to Albumin-Bound Paclitaxel in Head and Neck Cancer Patients. Translational Oncology, 2, 59-64. http://dx.doi.org/10.1593/tlo.09109

[11] Desai, N., Trieu, V., Yao, Z., Louie, L., Ci, S., Yang, A., et al. (2006) Increased Antitumoral Activity, Intratumor Paclitaxel Concentrations, and Endothelial Cell Transport of Cremophor-Free, Albumin-Bound Paclitaxel, ABI-007, Compared with Cremophor-Based Paclitaxel. Clinical Cancer Research, 12, 1317-1324. http://dx.doi.org/10.1158/1078-0432.CCR-05-1634

[12] Gelderblom, H., Verweij, J., Nooter, K. and Sparreboom, A. (2001) Cremophor EL: The Drawbacks and Advantages of Vehicle Selection for Drug Development. European Journal of Cancer, 37, 1590-1598. http://dx.doi.org/10.1016/S0959-8049(01)00171-X

[13] Gradishar, W. (2006) Albumin-Bound Paclitaxel: A Next-Generation Taxane. Expert Opinion on Pharmacotherapy, 7, 1041-1053. http://dx.doi.org/10.1517/14656566.7.8.1041

[14] Frese, K., Neesse, A., Cook, N., Bapiro, T.E., Lolkema, M.P., Jodrell, D.I. and Tuveson, D.A. (2012) nab-Paclitaxel Potentiates Gemcitabine Activity by Reducing Cytidine Deaminase Levels in a Mouse Model of Pancreatic Cancer. Cancer Discovery, 2, 260-269.

[15] Von Hoff, D.D., Ervin, T., Arena, F., Chiorean, E.G., Infante, J., Moore, M., et al. (2013) Increased Survival in Pancreatic Cancer with nab-Paclitaxel plus Gemcitabine. The New England Journal of Medicine, 369, 1691-1703. http://dx.doi.org/10.1056/NEJMoa1304369

[16] Eisenhauer, E., Therasse, P., Bogaerts, J., Schwartz, L.H., Sargent, D., Ford, R., et al. (2009) New Response Evaluation Criteria in Solid Tumors: Revised RECIST Guideline (Version 1.1). European Journal of Cancer, 45, 228-247. http://dx.doi.org/10.1016/j.ejca.2008.10.026

[17] Valle, J., Wasan, H., Palmer, D., Cunningham, D., Anthoney, A., Maraveyas, A., et al. (2010) Cisplatin plus Gemcitabine versus Gemcitabine for Biliary Tract Cancer. The New England Journal of Medicine, 362, 1273-1281. http://dx.doi.org/10.1056/NEJMoa0908721 